\title{
Nurse Practitioner Autonomy and Relationships with Leadership Affect Teamwork in Primary Care Practices: a Cross-Sectional Survey
}

\author{
Lusine Poghosyan, PhD, MPH, RN, FAAN and Jianfang Liu, PhD, MAS \\ Columbia University School of Nursing, New York, NY, USA.
}

BACKGROUND: The Nurse Practitioner (NP) workforce represents a substantial supply of primary care providers able to contribute to meeting a growing demand for care. However, controversy exists regarding the expanding role of NPs in primary care in terms of challenging the teamwork between NPs and physicians. To date, no empirical evidence exists regarding how to promote teamwork in primary care between NPs and physicians.

OBJECTIVE: We investigated whether NP autonomy within primary care practices and the relationships they have with leadership affect teamwork between NPs and physicians.

DESIGN: Using a cross-sectional survey design, data was collected from 163 primary care practices in Massachusetts.

PARTICIPANTS: Three hundred and fourteen primary care NPs completed and returned the mail survey yielding a response rate of $40 \%$.

MAIN MEASURES: The Autonomy and Independent Practice (AIP) and NP-Administration Relations (NP-AR) scales were used to measure NP independent practice and the relationships with leadership, respectively. These measures were aggregated to the practice level. Teamwork between NPs and physicians was measured at the individual NP level using the Teamwork (TW) scale. KEY RESULTS: The multilevel linear regression models investigated the influence of practice-level NP autonomy and the relationship between NPs and leadership on teamwork. With every unit increase on the practice-level mean score of AIP centered at the grand mean, the mean TW score increased by 0.271 units $(p<0.0001)$. With every unit increase of NP-AR centered at the grand mean, the mean TW score increased by $0.375(p<0.001)$. Over one-third (41.3\%) of the variance in teamwork could be explained by the final model.

CONCLUSION: The study findings demonstrate that NP autonomy and favorable relationships with leadership improve teamwork. Policy and organizational change should focus on promoting NP autonomy and improving the relationship between NPs and leadership to improve teamwork and consequently improve patient care and outcomes.

Electronic supplementary material The online version of this article (doi:10.1007/s11606-016-3652-z) contains supplementary material, which is available to authorized users.

Received May 15, 2015

Revised December 4, 2015

Accepted February 18, 2016

Published online March 7, 2016
KEY WORDS: primary care; nursing; workforce.

J Gen Intern Med 31(7):771-7

DOI: $10.1007 / \mathrm{s} 11606-016-3652-z$

(C) Society of General Internal Medicine 2016

\section{INTRODUCTION}

The implementation of national health reform with millions of people receiving insurance coverage is amplifying the existing challenges facing primary care. A major issue centers on how to increase capacity while improving quality and cost effectiveness. Policy makers and researchers are proposing innovative strategies and various workforce utilization models to assure the system is prepared as more people are gaining access. ${ }^{1,2}$ While some strategies seek to increase the number of primary care providers (PCPs), ${ }^{3,4}$ others seek to encourage efficient use of existing providers. ${ }^{5}$

Some policy initiatives, such as medical homes, focus on delivering team-based care to increase primary care capacity and improve patient outcomes. ${ }^{5}$ In high-functioning teams, with the aid of technology, PCPs could see almost five times more patients. ${ }^{1}$ In addition, outcomes are significantly better for patients who receive care from teams rather than from individual clinicians, ${ }^{6}$ especially when team members constantly interact and have a shared team vision. ${ }^{7}$ Thus, primary care is being transformed into care delivered in teams comprised of clinicians from multiple disciplines, including nurse practitioners (NPs) and physician assistants. ${ }^{8,9}$ Policy recommendations are supportive of this trend as a means to increase access, improve care, and control costs. ${ }^{10,11}$ To achieve these goals, primary care practices are implementing team-based models to optimally utilize the available workforce. ${ }^{2}$ However, one of the major debates surrounding team development in primary care revolves around the role and expanding scope of practice of NPs in teams that already have less defined and varied structures. ${ }^{12}$

State and organizational policies create confusion around NP roles. In some states, regulations require NPs to collaborate or be supervised by physicians, whereas in other states, these regulatory requirements have been removed by policy makers. ${ }^{13}$ Similarly, some organizations restrict NP practice or fail to provide necessary support so NPs can maximally contribute their advanced skills to teams. ${ }^{14,15}$

Teamwork between NPs and physicians in primary care has received attention due to their overlapping scopes of 
practice $^{16-18}$ and the fact that lack of agreement exists between them about their respective roles. ${ }^{19}$ Also, some call for restricting NP autonomy to assure effective primary care. ${ }^{16}$ Evidence is clear that patients benefit from care by interdisciplinary teams, ${ }^{6}$ and practices that promote teamwork, collegiality, and better relationships between providers and leadership provide better care. ${ }^{20-22}$ On the other hand, when patient care suffers, fragmented teamwork and poor collaboration and communication between team members are often found to be contributing factors, and the impact of errors resulting from poor teamwork can be detrimental for patient safety. ${ }^{23,24}$ Thus, effective teamwork is key in addressing access and quality of care challenges facing primary care; however, restricting the autonomy of certain team members might challenge it. A welldeveloped body of science in organizational studies suggests that incorporating individual team member autonomy in team designs is an effective approach to building successful teams. ${ }^{25,26}$ In teams, members should have autonomy while recognizing that their contributions to the team will vary given the differences in their expertise. In one study conducted with nurses in hospitals, researchers found that nurses' autonomy did not undermine teamwork between nurses and physicians, but rather, improved it. ${ }^{27}$ Leadership can play a vital role in promoting teamwork ${ }^{28,29}$ by engaging members into collaborative efforts and changing the organizational structures to better meet patients' and providers' needs. ${ }^{22,30,31}$

Despite the attention in recent years on primary care teams, we lack empirical evidence about how to promote teamwork. Moreover, there is no evidence regarding how NP autonomy - defined in the literature as NPs' ability to make independent care decisions ${ }^{15}$ - or how the relationships NPs have with leadership influence teamwork between NPs and physicians. Evidence is needed to help policy makers, administrators, and clinicians advocate for policy and organizational change that promote teamwork. This is especially important given the changing landscape of primary care, the shifting attention to team-based care, a predicted increase in NP numbers, ${ }^{32}$ and patients' openness to a greater role for NPs in their care. ${ }^{33}$ In this study, we investigated whether NP autonomy and independent practice and their relationships with leadership affect teamwork between NPs and physicians.

\section{METHODS}

\section{Design}

The study used a cross-sectional survey design. It was approved by the Institutional Review Board of Columbia University Medical Center.

\section{Measures}

We measured NP autonomy and independent practice and relationships with leadership using the Autonomy and
Independent Practice (AIP) and NP-Administration Relations (NP-AR) scales of the Nurse Practitioner Primary Care Organizational Climate Questionnaire (NP-PCOCQ), respectively. ${ }^{34} \mathrm{NP}-\mathrm{PCOCQ}$ is designed to measure primary care NP work context and has strong psychometric properties. ${ }^{34}$ The five-item AIP scale assesses NPs' perceptions of their ability to freely apply their knowledge and skills to provide care. The nine-item NP-AR scale measures the relationship between NPs and leadership. While there can be a wide variability across practices in terms of leadership structure, in prior work we found that NPs consider practice managers and medical directors as leadership. ${ }^{15,35}$ We created practice-level measures of AIP and NP-AR to demonstrate whether NPs from the same practice give consistent responses. Teamwork between NPs and physicians was measured at the individual NP level using the five-item Teamwork (TW) scale. ${ }^{36}$ For each item on the scales, NPs rate their response on a four-point scale: "l" strongly disagree; "2" disagree; " 3 " agree; and "4" strongly agree.

We also collected information about NPs including age, sex, education, and years of experience, and about practices including location (urban or non-urban), size (number of NPs), and type (physician office, community health center, etc.). NPs reported whether they have their own patient panel to whom they provide ongoing care.

\section{Sample and Survey Administration}

We identified NPs and their practices using the Massachusetts Provider Database (MPD), which was developed and is maintained by Massachusetts Health Quality Partners (MHQP), ${ }^{37}$ a coalition of health plans, hospitals, and government agencies in Massachusetts (MA). To update the MPD, MHQP contacts practices annually to request information about primary care physicians and specialists who are listed as providers for at least one of the five major health plans in MA. In 2011, for the first time, MHQP requested information about NPs, including their role as a PCP or NP specialist. In 2012, out of 1458 NPs identified by MHQP, 807 delivered primary care. We extracted their practice addresses and sent mail surveys to 807 NPs. Following a modified Dillman guide for surveys,${ }^{38}$ we sent a postcard reminder and conducted a second mailing to nonresponders. A convenience sample of 314 NPs returned the completed surveys, yielding a response rate of about $40 \%$ after accounting for ineligible NPs (i.e., not practicing in primary care) who worked in 163 practices. Their numbers in the practices ranged from 1 to 12 (mean: 1.85 and SD: 1.38).

\section{Data Analysis}

We first computed individual NP-level mean scores on the AIP and NP-AR scales for respondents who completed more than $70 \%$ of the scale items, ${ }^{39}$ then aggregated the scores of all NPs from each practice and computed the practice-level AIP and NP-AR scores and calculated intra-class correlations (ICCs). We created an NP-level TW scale by calculating the scale 
mean. Descriptive statistics on the scales and on demographic and work variables were computed. We examined the univariate associations between each potential predictor and the outcome variable.

We also performed a generalizability study on the scales to assess the measurement dependability ('reliability') ${ }^{40}$ and measurement errors from various sources. First, variance components from different sources were calculated; then $\mathrm{G}$ coefficients (Ep2) and Phi coefficients $(\Phi)$, as relative and absolute generalizability coefficients, respectively, were computed. ${ }^{41,42}$

We used multilevel linear regression models to investigate the influence of NP autonomy and independent practice and the relationship between NPs and leadership on teamwork. The models accounted for the hierarchical structure of the data, where 314 NPs (Level 1) were nested in 163 practices (Level 2). Significant covariates $(p<0.02)^{43}$ measuring NP characteristics were entered as Level 1 measures, and practicelevel characteristics were included as Level 2 measures. The main predictors were the practice-level AIP and NP-AR scores (Level 2 variables). We also assessed the "model fit" for each model and tested for multicollinearity. We considered $p$ values less than 0.05 to be significant. Data analysis was conducted in SAS Version 9.3 software $^{44}$ (See online Appendix).

\section{RESULTS}

Table 1 describes the sample demographic and work characteristics and their associations with teamwork. The average age of the participants was about 49 years, with the vast majority being female $(97.3 \%)$ and white $(93.3 \%) ; 47 \%$ of NPs practiced in physician offices. About $46 \%$ of NPs reported that they have their own patient panel to whom they deliver ongoing care. The practice-level ratio of NPs having their own panel indicated that on average, about half of NPs in each practice had their own patient panel. Only NP sex, highest nursing degree, and average number of hours worked per week were associated with teamwork. TW was correlated with AIP and NP-AR.

Both the relative and absolute generalizability coefficients for all scales were above 0.80 (Table 2), indicating that the measures were dependable ${ }^{45}$ or reliable ${ }^{40}$ (see online Appendix). We computed the means and standard deviations for all scale items (Table 2). The items measuring NP autonomy were ranked highly by NPs. NPs did not discuss every patient care detail with physicians, as evidenced by the item's high mean. The item measuring whether organizations create an environment for NPs to practice independently was ranked lowest compared to other scale items. Compared to AIP items, items on the NP-AR scale had lower mean scores. Administration sharing information with NPs and physicians and treating them in a similar manner were low-ranking items. The mean score on the AIP scale was 2.87 both at the NP and practice levels. Items in the TW scale measuring NPs' perception of physician support and having colleagues to ask for help were ranked highly. However, the item rating the degree that NPs and physicians practice as a team had the lowest mean score compared to other scale items.

Table 3 demonstrates the results from the multilevel linear regression models. The first model (Model 0), empty model, reflected variation in the intercept only at the individual level (Level 1), and did not include the hierarchical structure of the data. Next, Model 1 was built to include the hierarchical structure; the practices served as the higher level, Level 2. ICCs were calculated based on this model. By comparing the Akaike's Information Criterion ${ }^{46}$ between Models 0 and 1, we did not see improvement in Model 1. However, the result of ICC was 0.073 , higher than 0.05 , which validated the use of multilevel modeling. Then we built two separate models with only AIP and NP-AR as predictors, and a final model with both predictors. This model also included the significant covariates from the univariate analysis (sex, highest nursing degree, and average number of hours worked per week). We analyzed the interaction effect between Level-1 covariates and Level-2 predictors and did not find evidence to include any of them in the models. Models with and without Level-1 covariates as a random effect were also compared. None of them were significant, nor was there improvement in the model by including them. Variance Inflation Factor (VIF) was generated to check for multicollinearity. All VIF values were lower than 5 , indicating no multicollinearity concerns. The final model showed that the practice-level AIP and NP-AR had a positive effect on the NP-level teamwork. With every unit increase on the practice-level mean score of AIP centered at the grand mean, the mean TW score increased by 0.271 units $(p<0.001)$. With every unit increase on NP-AR centered at the grand mean, the mean TW score increased by 0.375 $(p<0.001)$. Over one-third $(41.3 \%)$ of the variance in teamwork could be explained by the final model. None of the control variables was significant.

\section{DISCUSSION}

We investigated NP autonomy and independent practice, the relationships NPs have with leadership, and their influence on teamwork in primary care practices. We found that NPs rate their relationship with physicians favorably. In contrast, many NPs report poor relationships with leadership. Participants perceived communication between NPs and leadership as fragmented and noted disparities in the way administrators shared information with physicians compared to NPs. Our results also demonstrate a significant relationship between NP autonomy and independent practice, NP-leadership relations, and teamwork. They suggest that supporting NP autonomy within primary care practices and improving NP-leadership relationships can positively influence teamwork between NPs and physicians.

Even though a convenience sample of NPs participated in our study, the sample's demographic characteristics are 
Table 1. NP- and Practice-Level Characteristics and their Association with Teamwork Scale

\begin{tabular}{|c|c|c|c|c|}
\hline Level 1: Individual NP-level characteristics & $N=314$ & Teamwork scale mean (SD) & $\begin{array}{l}\text { Pearson's correlation } \\
\text { with teamwork }\end{array}$ & $p$ value* \\
\hline \multicolumn{5}{|l|}{ Demographic } \\
\hline Age (years) & & & 0.06 & 0.33 \\
\hline Mean (SD) & $49.3(11.1)$ & & & \\
\hline Range & $26-71$ & & & \\
\hline $\operatorname{Sex} N(\%)$ & & & & $0.12 *$ \\
\hline Female & $291(97.3)$ & $3.52(0.47)$ & & \\
\hline Male & $8(2.7)$ & $3.25(0.42)$ & & \\
\hline Race N (\%) & & & & 0.39 \\
\hline White & $280(93.3)$ & $3.51(0.63)$ & & \\
\hline Non-white & $17(6.7)$ & $3.41(0.47)$ & & \\
\hline Highest nursing degree N (\%) & & & & $0.05 *$ \\
\hline Master's degree/post-master's certificate & $279(92.1)$ & $3.52(0.48)$ & & \\
\hline Doctor of nursing practice (DNP) & $6(2.0)$ & $3.03(0.41)$ & & \\
\hline Other & $18(5.9)$ & $3.49(0.42)$ & & \\
\hline Married N (\%) & & & & 0.64 \\
\hline Yes & $210(73.7)$ & $3.52(0.47)$ & & \\
\hline \multirow{2}{*}{\multicolumn{5}{|c|}{ Work }} \\
\hline & & & & \\
\hline Years in current position N $(\%)$ & & & & 0.43 \\
\hline Less than 1 year & $18(5.9)$ & $3.40(0.44)$ & & \\
\hline $1-6$ years & $114(37.6)$ & $3.48(0.48)$ & & \\
\hline More than 7 years & $171(56.4)$ & $3.54(0.47)$ & & \\
\hline Average hours worked per week N (\%) & & & & $0.14^{*}$ \\
\hline $1-20 \mathrm{~h}$ & $23(7.6)$ & $3.51(0.43)$ & & \\
\hline $21-40 \mathrm{~h}$ & $200(66.2)$ & $3.54(0.46)$ & & \\
\hline More than $40 \mathrm{~h}$ & $79(26.2)$ & $3.42(0.51)$ & & \\
\hline \multicolumn{4}{|l|}{ Have own patient panel N (\%) } & 0.38 \\
\hline Yes $r$ & $132(46.0)$ & $3.49(0.52)$ & & \\
\hline No & $155(54.0)$ & $3.54(0.44)$ & & \\
\hline Level 2: Practice-level characteristics & $N=163$ & & & $p$ value* \\
\hline Main practice site N (\%) & & & & 0.34 \\
\hline Physician's office & $75(47.2)$ & $3.52(0.44)$ & & \\
\hline Community health center & $34(21.4)$ & $3.55(0.49)$ & & \\
\hline Hospital-based clinic & $31(19.5)$ & $3.42(0.53)$ & & \\
\hline Other & 19 (11.9) & $3.49(0.49)$ & & \\
\hline \multicolumn{4}{|l|}{ Practice Location N (\%) } & 0.24 \\
\hline Urban & $75(46.9)$ & $3.53(0.48)$ & & \\
\hline Non-urban & $85(53.1)$ & $3.46(0.50)$ & & \\
\hline \multicolumn{4}{|l|}{ Number of NPs in each practice N (\%) } & 0.47 \\
\hline 1 & $12(7.5)$ & $3.41(0.62)$ & & \\
\hline $2-6$ & $104(65.4)$ & $3.51(0.48)$ & & \\
\hline $7-11$ & $22(13.8)$ & $3.53(0.44)$ & & \\
\hline More than 11 & $21(13.2)$ & $3.49(0.46)$ & & \\
\hline \multicolumn{3}{|l|}{ Practice-level patient panel ratio } & -0.03 & 0.59 \\
\hline Mean (SD) & $0.49(0.45)$ & & & \\
\hline Range & $0.00-1.00$ & & & \\
\hline \multicolumn{3}{|l|}{ Autonomy and independent practice } & 0.41 & $<0.0001$ \\
\hline Mean (SD) & $3.56(0.41)$ & & & \\
\hline Range & $2.40-4.00$ & & & \\
\hline \multicolumn{3}{|l|}{ NP-administration relations } & 0.55 & $<0.0001$ \\
\hline Mean (SD) & $2.87(0.64)$ & & & \\
\hline Range & $1.00-4.00$ & & & \\
\hline
\end{tabular}

* $p$ values are from the univariate analysis. We used t-tests or ANOVAs for categorical variables and Pearson's correlations for continuous variables. The variables with $p$ values $<0.20$ were included in the multilevel regression analysis

comparable to those of a national sample. ${ }^{47}$ For example, the average age of NPs was 49.3 years compared to 48 years in the National Sample Survey of NPs conducted in 2012. Our sample had more white NPs, which might be representative of the population in Massachusetts. We were unable to find information about the demographics of NPs in Massachusetts, as the State Nursing Workforce Center that collects such information was suspended. ${ }^{48}$ We did not have information about the demographics of non-responders. Massachusetts enacted health reform similar to the Affordable Care Act in $2006,{ }^{49}$ and NP practice and care models might also be different. The reform provided about a half million residents with insurance and further strained the system, which was experiencing a shortage of primary care physicians. ${ }^{50}$ Legislation was passed in 2008 requiring insurers to recognize NPs as PCPs to meet demand. ${ }^{51,52}$ State-level policies may explain NPs' high ratings of their autonomy; the AIP mean score was higher than the midpoint of 2.5. Our findings should be interpreted in this context.

More than half of the NPs did not have their own patient panels. Even within the same practice some NPs had their own patient panels, while others did not. We did not ask NPs for an explanation for such arrangements, but these arrangements could be explained by the relationship between NPs and physicians. Studies show that some physicians are more likely than others to routinely work with NPs and promote NPs' 
Table 2. Descriptive Statistics of Autonomy and Independent Practice, NP-Administration Relations, and Teamwork Scale Items

\begin{tabular}{|c|c|c|}
\hline Items & Mean & SD \\
\hline \multicolumn{3}{|c|}{ Autonomy and Independent Practice Scale (G Coefficient $($ Ep2 $)=0.84$; Phi Coefficient $(\Phi)=0.82)$} \\
\hline Do not have to discuss every patient care detail with a physician & 3.72 & 0.52 \\
\hline Freely apply knowledge and skills to provide patient care & 3.60 & 0.55 \\
\hline Organization does not restrict NP abilities to practice within scope of practice & 3.42 & 0.70 \\
\hline Provide all patient care within scope of practice & 3.55 & 0.60 \\
\hline Organization creates an environment to practice independently & 3.38 & 0.68 \\
\hline NP-Level Scale Score $(n=314)$ & 3.53 & 0.47 \\
\hline Practice-Level Scale Score $(n=163)$ & 3.56 & 0.41 \\
\hline \multicolumn{3}{|l|}{ NP-Administration Relations Scale $(\mathrm{G}$ Coefficient $(\mathrm{Ep} 2)=0.94 ;$ Phi Coefficient $(\Phi)=0.92)$} \\
\hline Valued by organization & 3.31 & 0.72 \\
\hline Regularly get feedback about performance from organization & 2.86 & 0.80 \\
\hline \multicolumn{3}{|l|}{ Administration: } \\
\hline Open to NP ideas to improve patient care & 3.12 & 0.75 \\
\hline Takes NP concerns seriously & 3.02 & 0.82 \\
\hline Shares information equally with NPs and physicians & 2.81 & 0.92 \\
\hline Treats NPs and physicians equally & 2.39 & 0.84 \\
\hline Informs NPs about changes taking place in the organization & 2.92 & 0.83 \\
\hline Makes efforts to improve working conditions for NPs & 2.81 & 0.79 \\
\hline Constantly communicates with NPs & 2.68 & 0.87 \\
\hline NP-Level Scale Score $(n=314)$ & 2.87 & 0.66 \\
\hline Practice-Level Scale Score $(n=163)$ & 2.87 & 0.64 \\
\hline \multicolumn{3}{|l|}{ Teamwork Scale $(G$ Coefficient $(E p 2)=0.87$; Phi Coefficient $(\Phi)=0.85)$} \\
\hline Valued by physician colleagues & 3.38 & 0.66 \\
\hline Physicians and NPs practice as a team & 3.35 & 0.74 \\
\hline NPs and physicians collaborate to provide patient care & 3.47 & 0.63 \\
\hline Have colleagues to ask for help & 3.67 & 0.50 \\
\hline Physicians support NP patient care decisions & 3.61 & 0.49 \\
\hline$N P$-Level Scale Score $(n=314)$ & 3.49 & 0.49 \\
\hline Practice-Level Scale Score $(n=163)$ & 3.49 & 0.47 \\
\hline
\end{tabular}

Strongly disagree $=1 ;$ disagree $=2 ;$ agree $=3 ;$ and strongly agree $=4$

roles, particularly those who are familiar with the NP role and have been practicing longer. ${ }^{53,54}$ NPs lacking their own patient panels within and across practices may not only limit NPs' contributions to care, but may also avert patients from the benefits of continuous primary care, which is critical for positive outcomes. ${ }^{55-57}$ Continuity of primary care, measured as the highest concentration of a patient's total visits to a single provider, has been shown to significantly reduce preventable hospitalizations. ${ }^{58}$ Taking advantage of NPs' advanced skills and allowing NPs to have their own panels within primary care teams in which they can leverage the expertise of other team members when necessary can be a strategy for increasing primary care capacity. Effective deployment of NPs is important especially when future workforce projections indicate a lack of appropriate personnel capable of staffing primary care teams to meet the growing burden of chronic diseases. ${ }^{59}$ More research is needed in this area.

While some suggest that NP autonomy in primary care teams be restricted, it may lead to an unwanted consequence of poor teamwork. Our results suggest that NP autonomy would not undermine teamwork, but rather, bolster it. In practices where NP autonomy is promoted, NPs may be more engaged in teamwork without feeling their practice is restricted by physicians. On the other hand, restrictions may further confuse the distinct roles and professional practices of NPs and physicians. Leadership can take actions to promote NP autonomy within their organizations, consequently improving teamwork.

We also looked at how the relationship between NPs and leadership creates a context for teamwork. Teamwork

Table 3. Multilevel Models of Effects of Practice-Level NP Independent Practice and NP-Leadership Relations on Teamwork

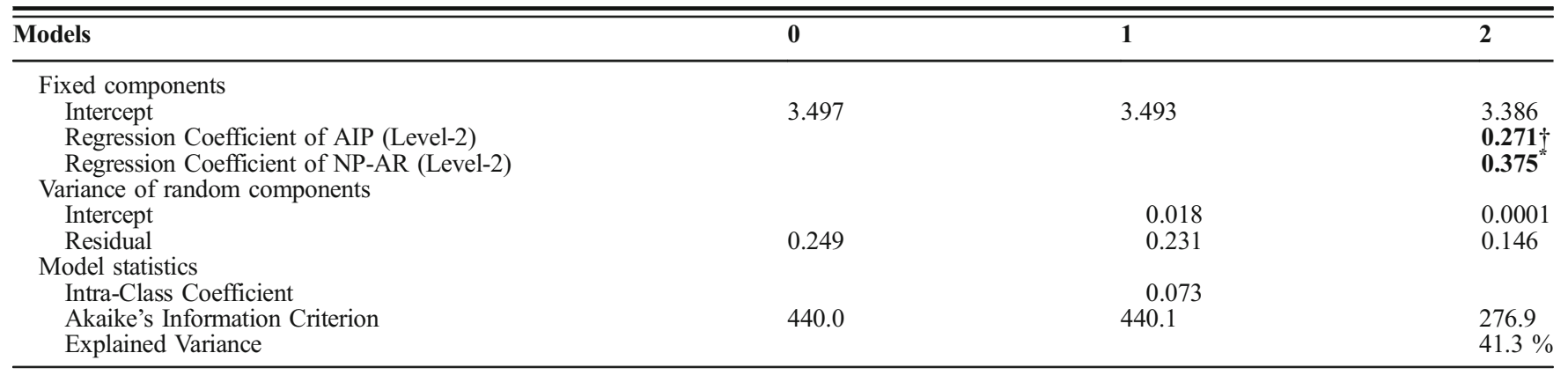

AIP Autonomy and Independent Practice, NP-AR NP-Administration Relations. Models including Level-1 covariates as random effects are not in the table. This information is available upon request. Final model, or Model 2, controlled for the effects of sex, education, and high workload, which were significant at $p$ values $<0.20$ in bivariate testing. ${ }^{*} p<0.001 ; \neq p<0.0001$ 
between NPs and physicians was negatively impacted by poor relationships between NPs and the leadership who neither view all PCPs similarly, nor provide them with similar access to information and resources. If NPs act in a PCP role, then they need access to similar resources as other PCPs to deliver high quality care. Administrators' lack of understanding of the NP role could explain this existing disparity. If leadership prevents access to resources for some team members, in this case for NPs, while promoting access for others, it creates an imprint of inequity and gives more value to one role than another, thus affecting the team dynamics and relationships between team members. To date, the administrators' constraint of NP practice in primary care and its impact on teamwork has been underestimated, and it will be a major problem in the future as NPs are increasingly employed in large group practices.

\section{Future Research}

More research is needed to better understand different forms of teamwork taking place in primary care from the perspectives of all PCPs. A more long-term strategy is to determine the appropriate and effective mix of clinicians comprising these teams. Studies should be conducted to determine which forms of teamwork are better for certain patient care processes and outcomes. We need evidence to guide optimal interprofessional team construction, to design interventions for team management, and to identify robust and efficient teamwork forms to address the demand for care and improve outcomes.

\section{Limitations}

The study has limitations. We collected data only in one state. NPs practicing in other states may have different experiences, which should be studied. State-level regulations determining the legal nature of the relationship between NPs and physicians may affect NPs' perception of teamwork. This study relied on self-reports of NPs. Non-response is an issue even though the response rate we achieved is comparable to that in other nurse surveys. ${ }^{60}$ Studies of nurse-reported measures obtained through surveys found no significant differences between responders and non-responders. ${ }^{61,62}$ Another limitation is that physicians were not surveyed to understand teamwork from their perspectives, which might be different from those of NPs. This restricts our understanding of teamwork. Future work should focus on their perspectives. Finally, we did not collect any information about how many other PCPs worked in practices. NPs from smaller practices might respond differently to our survey than NPs from larger practices.

Acknowledgements: We thank Massachusetts Health Quality Partners for the data sharing. Funding: Agency for Healthcare Research and Quality [R03 HSO20999]; Robert Wood Johnson Foundation.
Corresponding Author: Lusine Poghosyan, PhD, MPH, RN, FAAN; Columbia University School of Nursing, 617 West 168th Street, New York, NY 10032, USA (e-mail: lp2475@cumc.columbia.edu).

\section{Compliance with Ethical Standards:}

Conflict of Interest: The authors declare that they do not have a conflict of interest.

\section{REFERENCES}

1. Green LV, Savin S, Lu Y. Primary care physician shortages could be eliminated through use of teams, nonphysicians, and electronic communication. Health Aff. 2013;32(1):11-9.

2. Ladden MD, Bodenheimer T, Fishman NW, et al. The emerging primary care workforce: preliminary observations from the primary care team: learning from effective ambulatory practices project. Acad Med. 2013;88(12): 1830-4.

3. Patient Protection and Affordable Care Act. Act of 2010. Public Law 111148, 124 Stat. 119 thru 124 Stat. 1025. March 23, 2010.

4. Schoenthaler AM, Schwartz BS, Wood C, Stewart WF. Patient and physician factors associated with adherence to diabetes medications. Diabetes Educ. 2012;38(3):397-408.

5. National Committee for Quality Assurance. Patient-Centered Medical Home. Available at: http://www.ncqa.org/Programs/Recognition/Practices/ PatientCenteredMedicalHomePCMH.aspx. Accessed 2 February 2016.

6. Litaker D, Mion LC, Planavsky L, Kippes C, Mehta N, Frolkis J. Physician-nurse practitioner teams in chronic disease management: the impact on costs, clinical effectiveness, and patients' perception of care. J Interprof Care. 2003;17(3):223-37.

7. Mundt MP, Gilchrist VJ, Fleming MF, Zakletskaia LI, Tuan W, Beasley JW. Effects of primary care team social networks on quality of care and costs for patients with cardiovascular disease. Ann Fam Med. 2015; 13(2): 139-48.

8. Agency for Healthcare Research and Quality. Primary care workforce facts and stats No. 3: distribution of the U.S. primary care workforce. Available at: http://www.ahrq.gov/research/findings/factsheets/primary/ pcwork3/index.html. Accessed 2 February 2016.

9. Stange K. How does provider supply and regulation influence health care markets? Evidence from nurse practitioners and physician assistants. J Health Econ. 2014;33:1-27.

10. Institute of Medicine. The future of nursing: leading change, advancing health. Available at: http://www.iom.edu/Reports/2010/The-Futureof-Nursing-Leading-Change-Advancing-Health.aspx. Accessed 2 February 2016.

11. Rand Health. Controlling health care costs in Massachusetts: an analysis of options. Available at: http://www.rand.org/pubs/technical_reports/ TR733.html. Accessed 2 February 2016.

12. Grover A, Niecko-Najjum LM. Primary care teams: are we there yet? Implications for workforce planning. Acad Med. 2013;88(12):1827-9.

13. Pearson LJ. The Pearson Report 2012: the annual state-by-state national overview of nurse practitioner legislation and healthcare issues. Am J Nurs Pract. 2012;12(2):1-60.

14. Poghosyan L, Shang J, Liu J, Poghosyan H, Liu N, Berkowitz B. Nurse practitioners as primary care providers: creating favorable practice environments in New York State and Massachusetts. Health Care Manag Rev. 2015;40(1):46-55.

15. Poghosyan L, Nannini A, Stone P, Smaldone A. Nurse practitioner organizational climate in primary care settings: implications for professional practice. J Prof Nurs. 2013;29(6):338-49.

16. American Academy of Family Physicians. Primary care for the 21st century: ensuring a quality, physician-led team for every patient. Available at: http://www.aafp.org/online/en/home/membership/initiatives/nps/patientcare.html. Accessed 2 February 2016.

17. Hansen KK, Zwanziger J. Marginal costs in general acute care hospitals: a comparison among California, New York and Canada. Health Econ. 1996;5(3): 195-216.

18. Anderson GM, Grumbach K, Luft HS, Roos LL, Mustard C, Brook R. Use of coronary artery bypass surgery in the United States and Canada. Influence of age and income. JAMA. 1993;269(13):1661-6.

19. Donelan K, DesRoches CM, Dittus RS, Buerhaus P. Perspectives of physicians and nurse practitioners on primary care practice. N Engl J Med. 2013;368(20): 1898-906. 
20. Bower P, Campbell S, Bojke C, Sibbald B. Team structure, team climate and the quality of care in primary care: an observational study. Qual Saf Health Care. 2003;12(4):273-9.

21. Grumbach $\mathbf{K}$, Bodenheimer T. Can health care teams improve primary care practice? JAMA. 2004;291(10):1246-51.

22. Linzer M, Manwell LB, Williams ES, et al. Working conditions in primary care: physician reactions and care quality. Ann Intern Med. 2009; 151(1):28-36.

23. Firth-Cozens J. Cultures for improving patient safety through learning: the role of teamwork. Qual Health Care. 2001;10(suppl 2):ii26-31.

24. Manser T. Teamwork and patient safety in dynamic domains of healthcare: a review of the literature. Acta Anaesthesiol Scand. 2009;53(2):143-51.

25. Langfred CW. The paradox of self-management: individual and group autonomy in work groups. J Organ Behav. 2000;21(5):563-85.

26. Hoeg1 M, Parboteeah P. Autonomy and teamwork in innovative projects. Human Resour Manag. 2006;45(1):67-79.

27. Rafferty A, Ball J, Aiken L. Are teamwork and professional autonomy compatible, and do they result in improved hospital care? Qual Health Care. 2001;10(suppl 2):ii32-7.

28. Regan S, Laschinger HK, Wong CA. The influence of empowerment, authentic leadership, and professional practice environments on nurses perceived interprofessional collaboration. J Nurs Manag. 2015. doi:10. $1111 /$ jonm. 12288.

29. Taplin SH, Foster MK, Shortell SM. Organizational leadership for building effective health care teams. Ann Fam Med. 2013;11(3):279-81.

30. O'Malley AS, Gourevitch R, Draper K, Bond A, Tirodkar MA Overcoming challenges to teamwork in patient-centered medical homes: a qualitative study. J Gen Intern Med. 2014;30(2):183-92.

31. Shanafelt TD, Gorringe G, Menaker R, et al. Impact of organizational leadership on physician burnout and satisfaction. Mayo Clin Proc. 2015;90(4):432-40.

32. Auerbach DI. Will the NP workforce grow in the future? New forecasts and implications for healthcare delivery. Med Care. 2012;50(7):606-10.

33. Dill MJ, Pankow S, Erikson C, Shipman S. Survey shows consumers open to a greater role for physician assistants and nurse practitioners. Health Aff. 2013;32(6):1135-42.

34. Poghosyan L, Nannini A, Finkelstein SR, Mason E, Shaffer J. Development and psychometric testing of the Nurse Practitioner Primary Care Organizational Climate Questionnaire (NP-PCOCQ). Nurs Res. 2013;62(5):325-34

35. Poghosyan L, Nannini A, Smaldone A, et al. Revisiting scope of practice facilitators and barriers for primary care nurse practitioners: a qualitative investigation. Policy Polit Nurs Pract. 2013;14(1):6-15.

36. Poghosyan L, Boyd D, Knutson AR. Nurse practitioner role, independent practice, and teamwork in primary care. J Nurs Pract. 2014;10(7):472-9.

37. Massachusetts Health Quality Partners. Quality insights: clinical quality in primary care, 2011-2012. Available at: http://www.mhqp.org/measure and_report/?content_item_id=158. Accessed 2 February 2016.

38. Dillman DA, Smyth JD, Christian LM. Internet, Mail, and Mixed-Mode Surveys: The Tailored Design Method. 3rd ed. Hoboken: Wiley; 2009.

39. Bono C, Ried D, Kimberlin C, Vogel B. Missing data on the Center for Epidemiologic Studies Depression Scale: a comparison of 4 imputation techniques. Res Soc Adm Pharm. 2007;3(1):1-27.

40. Cronbach LJ, Gleser GC, Nanda H, Rajaratnam N. The Dependability of Behavioral Measurements. New York: Wiley; 1972.

41. Rentz JO. Generalizability theory: a comprehensive method for assessing and improving the dependability of marketing measures. J Mark Res. 1987;24(1):19-28.

42. Burns KJ. Beyond classical reliability: using generalizability theory to assess dependability. Res Nurs Health. 1998;21(1):83-90.

43. Hosmer DW, Lemeshow S. Applied Logistic Regression. 2nd ed. New York: Wiley; 2000.
44. SAS Institute Inc. Base $\mathrm{SAS} \circledast 9.3$ Procedures Guide. Cary: SAS Institute Inc; 2013.

45. Tobin K, Roth w. Teaching to Learn: A View from the Field. Rotterdam: Sense Publisher; 2006.

46. Singer J. Using SAS PROC MIXED to fit multilevel models, hierarchical models, and individual growth models. J Educ Behav Stat. 1998;23(4):323-55.

47. Health Resources and Services Administration. Highlights from the 2012 National Sample Survey of Nurse Practitioners. Available at: http://bhpr. hrsa.gov/healthworkforce/supplydemand/nursing/nursepractitionersurvey/npsurveyhighlights.pdf. Accessed 2 February 2016

48. Robert Wood Johnson Foundation. Three State Nursing Workforce Centers Suspend Operations 2012. Available at: http://www.rwjf.org/en/library/ articles-and-news/2012/08/three-state-nursing-workforce-centers-suspend-operations.html. Accessed 2 February 2016

49. Commonwealth of Massachusetts. Chapter 58 of the Acts of 2006: An act providing access to affordable, quality, accountable health care 2006. Available at: http://www.mass.gov/legis/laws/seslaw06/sl060058.htm. Accessed 2 February 2, 2016.

50. Massachusetts Medical Society. Physician workforce study 2010. Available at: http://www.massmed.org/News-and-Publications/MMS-NewsReleases/2010-Physician-Workforce-Study-Shows-5-Consecutive-Yearsof-Primary-Care-Shortages/\#.VrD5XfkrKUk. Accessed 2 February 2016.

51. Commonwealth of Massachusetts. Chapter 305 of the Acts of 2008: An act to promote cost containment, transparency and efficiency in the delivery of quality health care. Available at: http://www.mass.gov/legis/laws/ seslaw08/sl080305.htm. Accessed 2 February 2016.

52. Craven G, Ober S. Massachusetts nurse practitioners step up as one solution to the primary care access problem: a political success story. Policy Polit Nurs Pract. 2009;10(2):94-100.

53. Peterson LE, Blackburn B, Petterson S, Puffer JC, Bazemore A, Phillips RL. Which family physicians work routinely with nurse practitioners, physician assistants or certified nurse midwives. J Rural Health. 2014;30(3):227-34.

54. Street D, Cossman JS. Does familiarity breed respect? Physician attitudes toward nurse practitioners in a medically underserved state. J Am Acad Nurse Pract. 2010;22(8):431-9.

55. Fan VS, Burman M, McDonell MB, Fihn SD. Continuity of care and other determinants of patient satisfaction with primary care. J Gen Intern Med. 2005;20(3):226-33.

56. Nutting PA, Goodwin MA, Flocke SA, Zyzanski SJ, Stange KC. Continuity of primary care: to whom does it matter and when? Ann Fam Med. 2003; 1(3):149-55.

57. Cabana MD, Jee SH. Does continuity of care improve patient outcomes? J Fam Pract. 2004;53(12):974-80.

58. Nyweide DJ, Anthony DL, Bynum JP, et al. Continuity of care and the risk of preventable hospitalization in older adults. JAMA Intern Med. 2013;173(20):1879-85.

59. Bodenheimer T, Chen E, Bennett HD. Confronting the growing burden of chronic disease: can the U.S. health care workforce do the job? Health Aff. 2009;28(1):64-74.

60. Aiken LH, Sloane DM, Clarke S, et al. Importance of work environments on hospital outcomes in nine countries. Int $\mathrm{J}$ Qual Health Care. 2011;23(4):357-64.

61. Smith HL. A double sample to minimize bias due to non-response in a mail survey. In: Ruiz-Gazen A, Guilbert P, Haziza D, Tille Y, eds. Survey Methods: Applications to Longitudinal Studies, Health, Electoral Studies, and to Studies in Developing Countries. Paris: Dunod [in French]; 2008:334-9.

62. Aiken LH, Sloane DM, Cimiotti JP, et al. Implications of the California nurse staffing mandate for other states. Health Serv Res. 2010:45(4):904-21. 